\title{
Conceptual based on the Data Mining Techniques for the Prediction of Hydration Assessment, Breath Analysis and Heart Disease
}

\author{
K.SaiManoj
}

\begin{abstract}
-both the facts mining and medicinal offerings corporation have risen some of robust early area frameworks and amazing well being associated frameworks from the scientific and locating facts. With the fast developing of health associated facts advances it's miles quite simple for the health care providers to examine and save extremely good measures of Patent data. For the effective usage of this statistics for the improvement of the best outcomes within the medicinal services and manner, properly-being professionals need to differentiate the best measures and comply with the proper research techniques for the sort of statistics within acquire. This audit Paper has merged at the information digging strategies for the evaluation of Hydration reputation via Breathe examination and furthermore usage of data digging structures for the expectancy of heart sickness.
\end{abstract}

Keywords-statistics Mining, health care enterprise, Hydration recognition Breathe studies, coronary heart infection.

\section{INTRODUCTION}

in this exploration artwork we tested on the restorative facts mining has been a large dormant technique for investigating hidden examples in informational collections of healing circle. In medicinal offerings, regardless of the way that facts mining isn't always drastically carried out, its notoriety presently little by little stated within the healing datasets for its preceding revelation motion. facts mining can brighten up selection-production by means of way of finding examples and styles in a variety of multifaceted statistics. There are boss objectives of records miningexpectation and depiction. Forecast consists of some factors or fields in the informational series to visualize baffling or

destiny estimations of various factors of hobby. Then all over again story centers around choice designs recitation of the records that can be deciphered with the aid of human beings. The records created with the aid of the properlybeing institutions is great and multifaceted because of which it is burdened to discover the records, in order to make noteworthy declaration concerning affected person's fitness. This statistics incorporates insights approximately emergency clinics, patients, healing confirm, healing fee and so on. thus, there can be an unquestionable requirement to make a telling equipment for investigating and eliminating noteworthy information from this mind boggling statistics. The exam of fitness information improves the human offerings with the aid of way of upgrading the display of affected person affiliation errands. The effects made by way of manner of data Mining advances enhance the movement

Revised Manuscript Received on September 14, 2019.

Dr.K.SaiManoj, CEO, Innogeecks Technologies and Amrita Sai Institute of Science and Technology, Vijayawada, AndhraPradesh, India

(E-mail: ceo@innogeecks.com) of foreseeing the identical patients and bunching them underneath a tough collecting depending on ailment or properly being issues, so social coverage contribution gives them strong capsules. it may likewise be powerful for estimating the kind of existence of sufferers in medical institution, for medicinal examination and developing affiliation for efficacious statistics framework the executives

The growing reception of records enhancements in social insurance and the accessibility of increasingly tolerant statistics and associated medicinal services factors supply new possibilities to using investigation to have an impact on health results. in recent times, maximum medicinal offerings associations have a few shape of social insurance statistics innovation set up (for instance digital scientific document [EMR]), which lets in them to gauge and seize know-how data steadily and at the factor the eye. consequently, providers have at their mien widespread measures of information, which they've to reveal

into beneficial records and records that would equip towards improving well-being consequences.

actual techniques, for example, prescient showing and facts mining are very valuable to break down and decipher the undertakings to increase the statistics spherical there with the useful resource of inspecting severa tactics to deal with the exam of 3 social coverage troubles. inside the number one exam, we use data mining strategies to assess hydration reputation utilising breath exams. thru the massive research of the in excess of three hundred unpredictable natural mixes contained in human breath, we imply to differentiate markers of hydration. For the following issue, get familiar with the diverse facts mining techniques and furthermore examine on the correct calculation that's suitable for the expectancy of coronary infection making use of facts mining tool. numerous research demonstrated that a extraordinary ldl cholesterol and has a few alternatives; and growing its stages is typically recommended for the great well being.

\section{WRITING SURVEY\& METHODOLOGY}

I) Hydration appraisal

approximately sixty $3 \%$ of the human weight is water, that's fundamental for digestion, temperature guiding 


\section{CONCEPTUAL BASED ON THE DATA MINING TECHNIQUES FOR THE PREDICTION OF HYDRATION ASSESSMENT, BREATH ANALYSIS AND HEART DISEASE}

principle and extraordinary physiological paperwork that upload to extraordinary health. dietary varieties, sicknesses, strenuous work, exercising session, amongst different every day physical activities can adjust the everyday water necessities for a person. certainly, even a negligible loss of hydration of $-1 \%$ or $-2 \%$ of weight can negatively have an execution [1]. on the outrageous, severe parchedness, each beneficial (e.G., in sports activities rivalries to reach at a specific weight) or surprising, affords a important well being danger that would even bring about dying [2]. in any case, growing evidence suggests that mellow loss of hydration may additionally likewise represent the improvement of various morbidities [3]. simultaneously, incredible hydration has been regarded to reduce the hazard of ceaseless illnesses, as an example, stoppage, exercise bronchial bronchial asthma, hyperglycemia, amongst others [4]. ultimately, the importance of suitable hydration and of using sturdy and specific strategies to screen and verify even little adjustments in human hydration ranges turns into clean [1, 2].

II) Breath examination and VOCs Human breath consists of nitrogen, oxygen, carbon dioxide, water, latent gases and extra than 1000

unpredictable herbal mixes (VOCs). these VOCs can be remoted into severa concoction training which includes hydrocarbons, alcohols, ketones, aldehydes, esters and heterocycles. no longer in any respect like NO and different inorganic gases, VOCs are essentially blood-borne, and might reflect an normal physiological biochemical approach or an obsessive circumstance in someone.

Synopsis of Key research needs and specific aims

From the writing survey, we're capable of separate the accompanying most important topics:

i) Dehydration has poor results in our desired health

ii) (accurate) evaluation of hydration reputation is hard

iii) there is no splendid high-quality famous for estimating hydration fame

iv) extra basic techniques require series of natural beverages

v) most techniques have poor intra-and among close to home reproducibility

vi) Breath checks are noninvasive and efficaciously rehashed We proposed breath studies as some other method to gauge hydration recognition through examining the behavior

of VOCs in breathed out breath. We commenced out with an underlying exploratory research to survey whether hydration reputation in grown-united states of americamay be anticipated thru breath examination. Investigations had been directed from an example of greater than 40 sound subjects, ages 18 to forty.

data mining techniques had been utilized to break down the breath tests and business enterprise hydrated as opposed to were given dried out human beings.

\section{technique}

\section{facts series}

The idea is to gather the breath checks regular with the headings of medical research bunch from the department of impact on highbrow capability, readiness and workout

carried out physiology at scientific studies lab. Human VOCs from the subjects' breath, clearly as specific hydration measures, to be amassed for assessment of hydration reputation. The de-identified dataset became then given to us to actual investigation.

topics

The subjects were volunteers from the clinical grounds. 40-six stable grown-up subjects, 23 men and 23 ladies, a long time 18-40 years of age to be take a look at from final

$1 / 4$ of a three hundred and sixty five days. topics are reject from the exam for the accompanying situations: diabetes, hypothyroid, hyperthyroid, claustrophobia, ebb and flow weight reduction diet, noteworthy weight reduction or addition (5\% of frame weight) over the maximum modern 3 months, liver disorder, for instance, hepatitis or cirrhosis, pregnancy, or the failure to stop from physical paintings or workout for two non-stop days at some stage in the investigation. teach and furthermore take before graduation of the studies as affirmed by using the scientific assessment Board. An internal state of affairs studies configuration might be applied in which every character went about as their non-public control. For this maximum green information mining technique, for example, Sampling calculation is specially unique.

III) heart illnesses can be caused due to type of additives:

hypertension: suppose when the coronary heart siphons blood, the energy of the blood pushes towards the dividers of the veins causing pressure. within the occasion that the weight rises and remains excessive past normal time it's miles called hypertension or hypertension that may damage the body from a pair of things of view that is expanding the risk of coronary coronary heart stroke or growing cardiovascular breakdown, kidney unhappiness and so forth.

acceleratedldl cholesterol: ldl cholesterol is a waxy substance observed in the greasy shops within the veins.

Increment in the greasy shops (expanded ldl cholesterol) does not permit adequate blood to circulate in via the veins inflicting breathing failures.

unfortunate weight loss program: consuming a further of reasonably-priced meals builds pulse and ldlldl cholesterol degree inflicting the danger of coronary episodes.

Smoking: it harms the arranging of deliver routes and fabricates a greasy cloth known as atheroma which limits the corridors causing cardiovascular disasters.

Absence of physical movement: absence of hobby expands ldl cholesterol degree in veins which similarly builds the danger of cardiovascular screw ups.

Corpulence: big humans are sure to have hypertension, elevated ldlldl cholesterol level and diabetes (increment in glucose level) which builds the chance of coronary heart strokes in human frame. in recent times, information mining is choosing up prevalence in human offerings business enterprise as this enterprise creates big measure of complicated facts about health facility assets, capsules, restorative gadgets, patients, contamination analysis and so on 
This unpredictable information must be organized and tested for statistics extraction if you want to

in addition assist in number one control and is moreover savvy.

To expect the coronary contamination with extra effectiveness records mining approach, for instance, MAFIA calculation is especially lower priced. it is called as Maximal frequent item set set of rules.

various data MINING equipment utilized in heart ailment PREDICTION device WITH ACCURACY

Abhishek et al in the year 2013 implemented records mining tool Weka three.6.four in coronary infection forecast framework utilizing J48 approach finished 90 five.fifty six\% exactness and the use of Naïve Bayes achie

Abhishek et al in the 365 days 2013 carried out records mining tool Weka three.6.four in coronary infection forecast framework utilizing J48 method completed ninety five.56\% precision and using Naïve Bayes completed ninety .forty two\%. [6]

Rashedur et al in the 12 months 2013 applied Neural tool approach making use of Weka statistics mining tool and done $79.19 \%$ and to have a look at one in every of a type grouping strategies, he applied a few different machine fluffy motive making use of TANGRA data mining device and achieved 80 three.eighty five $\%$ exactness. [7]

Nidhi et al inside the 365 days 2012 applied data mining device Weka three.6.6 inside the studies of coronary infection expectation framework and done ninety nine.Fifty $\%$ making use of Naive Bayes. She furthermore implemented TANGRA information mining tool however could accomplish as lots as fifty $.33 \%$ simply utilizing choice timber. She likewise tried .internet statistics mining device and finished as much as ninety six.5\% utilising neural systems. [5] Resul et al in the twelve months 2009 utilized SAS base programming

9.1.three mission 90 seven.four\% using neural structures. [8] information MINING strategies extensively utilized IN

end OF other sicknesses

Humar et al within the year 2008 implemented order, returned proliferation, Fuzzy neural device techniques for diabetes and coronary coronary heart ailments. [9]

Marcel et al within the yr 2007 applied Bayesian class for Characinoid coronary contamination. [10] Mohammad et al inside the year 2012 implemented C4.5 and C5.zero calculation for coronary infection and bosom malignant increase dedication. [11]

M. Akhil et al in the three hundred and sixty five days 2012 applied affiliated association and hereditary calculation for the analysis of bosom malignant growth, Pima Indian Diabetes and coronary infection. [12]

\section{QUIT\& RESULTS}

We accomplished a big writing compare to research the ebb and waft strategies for assessment of human hydration progresses on breath exam and from that, depict the nevertheless this kind of massive quantity of research wishes in the region. We examined some other approach to survey

hydration popularity making use of breath checks. Likewise we considered the impact of the execution of an virtual medicinal file framework at the tempo of inpatient prescription mistakes and unfavourable medication activities.

We saw that with the usage of the records mining methods to coronary contamination facts which calls for to be prepared, we will get powerful consequences and gain sturdy execution with the intention to assist in easy leadership in social coverage corporation.

\section{FUTURE PAINTINGS\& CONCLUSION}

utilizing this innovative and modern huge writing evaluation we're developing new efficient data Mining calculations and furthermore creative coding in MATLAB to predict the Hydration investigation, Breath examination, heart disease and malignant increase enjoyable the contemporary hints. For this we are doing regular imaginative studies with the organization of famous medicinal colleges specialists and scholars. we're taking customary specialised assist from the researchers, IT specialists, and medicinal specialists and furthermore from the Innogeecks advances Vijayawada.

\section{REFERENCES}

1. Armstrong, L.E., Hydration appraisal strategies Sustenance opinions, 2005. Sixty three(6): p. S40-S54.

2. Oppliger, R.A., et al., Accuracy of pee express gravity and osmolality as markers of hydration repute. common magazine of game nutrients andexercising Metabolism, 2005. 15(three): p. 236-251.

3. Manz, F., Hydration and disorder. Diary of the yankeeuniversity of nutrients, 2007. 26(suppl five):p. 535S-541S

4. Manz, F. furthermore, A. Wentz, The significance of correct hydration for the anticipation of ceaseless maladies.Sustenance reviews, 2005. Sixty 3: p. S2-S5.

5. NidhiBhatla and KiranJyoti, "An analysis of coronary heart ailment Prediction making use of different records Mining strategies", worldwide magazine of Engineering research and generation (IJERT),ISSN: 2278-0181,Vol. 1 difficulty 8, October -2012

6. Abhishektaneja, heart sickness Prediction machine the use of records Mining techniques, OrientalLogical Publishing Co., India, 2013.

7. Rashedur M. Rahman, FarhanaAfroz, assessment of numerous category strategies using distinctive statistics Mining tools for Diabetesdetermination, journal of software program Engineering and packages, 2013.

8. NidhiBhatlaKiranJyoti, An analysis of heart disease Prediction making use of different facts Mining strategies, international journal of Engineeringresearch and generation (IJERT), 2012.

9. HumarKahramanli, NovruzAllahverdi, design of a half breed framework for the diabetes and coronary coronary heartinfections, Elsevier, 2008.

10. Marcel A.J. Van Gerven, Predicting carcinoid coronary infection with the loud limit classifier, Elsevier, 2007.

11. Mohammad Taha Khan, Dr. ShamimulQamar and Laurent F. Massin, A Prototype of

12. Malignancy/heart sickness Prediction version the use of records Mining, global magazine of carried out Engineering research, 2012

13. M.Akhiljabbar, Dr.Priti Chandra, Dr.B.LDeekshatulu, coronary heart disorder Prediction gadget using 


\section{CONCEPTUAL BASED ON THE DATA MINING TECHNIQUES FOR THE PREDICTION OF HYDRATION ASSESSMENT, BREATH ANALYSIS AND HEART DISEASE}

Associative class and Genetic algorithm, worldwide convention on rising traits in electrical, Electronics and verbal exchange technologies, 2012

14. threat elements And protection troubles In various Cloud garage Operations Dr.k.SaiManoj extent-8 difficulty-12, October 2019, ISSN: 2278-3075 (online) published by way of: Blue Eyes Intelligence Engineering and Sciences booklet (First writer) (ELSEVIER Scopus)

15. Conceptual orientated investigation on the improvement of the Cloud facts garage protection Dr.k.SaiManoj international magazine of laptop technology tendencies and generation (IJCST) - extent 7 problem 5, Sep - Oct 2019.

16. Cloud protection: chance variables and protection problems in cutting-edge styles Dr.k.SaiManoj worldwide journal of Engineering and technology, technological know-how Publishing enterprise October 2019 (Scopus)

\section{ACKNOWLEDGEMENTS}

This paper heartily dedicated to beloved Honble Secretary and Correspondent Sri. K.Ram Mohan Garu, \&Smt.K.Bhavani Devi Garu Amrita Sai Institute of science and technology. Also to all the respected Amrita Sai Management members. My special thanks to the Innogeecks technologies, Vijayawada for their technical support in all the aspects.

\section{AUTHORS' INFORMATION}

Dr K SaiManoj, Founder and Executive Director of Innogeecks Global Services Pvt Ltd, Founder and CEO of Innogeecks Technologies and Founder of 3 start-ups based on IOT and Cloud Computing, is an Enthusiastic learner, Excellent Financial Advisor, Innovative and Visionary Leader, Insightful team builder and strategic planner, who has 10+ years of experience in Financial Services, Equity Research and IT- ITeS services to his credit. He has worked in Reputed Companies like WIPRO Technologies, Fidelity Inverstments.etc.,

He is Proud of achieving many laurels in the field of Computers and Research. He is a Certified Ethical hacker, Certified Computer hacking forensics Investigator, Certified Security Analyst, Charted Engineer from IEI (India), Certified Blockchain Expert, Microsoft Certified Technology Specialist, AWS Certified Solutions Architect-Associate, Google Analytics Individual Qualification, IBM Block chain Certification, Certified EC Council Instructor and so on

He has a proven record of having $10+$ certifications from the most sought after software giants such as Microsoft, IBM, Google, Face book, EC Council \& Amazon besides this he has acted as a reviewer for the Journal of Super Computing (Springer), Journal of Big Data (Springer) and Journal of the Institution of Engineers (India) - Series B (Springer). And also with his solid financial advice 21 start-ups of Kochi, Bangalore and Vijayawada have tread the success track.

Talking about his research excellence, it is exciting to know that he has filed 3 patents and 4 more are in pipeline and has Published more than 25 research papers in reputed journals like Thomas Reuters, IEEE, Scopus etc., and shows keenness in researching on Cyber Security, Cloud Computing, Big Data / Hadoop, Block chain and Data Analytics. 